\title{
Caudal anesthesia reduces the minimum alveolar concentration of enflurane for laryngeal mask air- way removal in boys
}

\author{
[L'anesthésie caudale permet de réduire la concentration alvéolaire minimale \\ d'enflurane pendant le retrait du masque laryngé chez des garçons]
}

Wen-Jing Xiao MD, Xiao-Ming Deng MD, Geng-Zhi Tang MD, Mao-Ping Lu MD, Kun-Ling Xu MD

Purpose: To investigate the effects of caudal analgesia on the minimal alveolar concentration of enflurane for laryngeal mask airway (LMA) smooth extubation (MACex).

Methods: We studied 50 nonpremedicated children, aged three to ten years, ASA physical status I, undergoing surgery for hypospadias repair. After a sevoflurane inhalation induction, children were randomized to receive LMA insertion with or without ropivacaine caudal analgesia. At the end of surgery, a predetermined end-tidal enflurane concentration was achieved, and the LMA was removed by an anesthesiologist blinded to group allocation. Each concentration at which LMA extubation was attempted was predetermined by the up-and-down method (with $0.1 \%$ as the step size). When LMA removal was accomplished without coughing, clenching teeth or gross purposeful muscular movements during or within one minute after removal, it was considered successful.

Results: MACex of enflurane for LMA removal in the group without caudal anesthesia was 1.04\% (95\% confidence interval, 1.00-1.10) and the LMA MACex of enflurane in the group with caudal anesthesia was $0.74 \%$ (95\% confidence interval, $0.63-0.81)$. Caudal analgesia significantly reduced enflurane requirements by $29 \%$ (95\% confidence interval, 22-36\%).

Conclusion: In conclusion, caudal analgesia significantly reduced the LMA MACex of enflurane by approximately $29 \%$. Possible mechanisms may be related to the analgesic effect of caudal blockade or to the sedative properties of neuraxial anesthesia.

Objectif: Rechercher les effets de l'analgésie caudale sur la concentration alvéolaire minimale d'enflurane utilisée pour faciliter l'extubation (CAMex) du masque laryngé (ML).

Méthode : Cinquante enfants de trois à dix ans, d'état physique ASA I, sans prémédication, devaient subir une réparation pour hypospadias.
Après l'induction de l'anesthésie par l'inhalation de sévoflurane, ils ont été répartis aléatoirement et ont reçu un $M L$ avec ou sans analgésie caudale avec de la ropivacaïne. À la fin de l'opération, on a administré de l'enflurane selon une concentration télédiastolique prédéterminée et le ML a été retiré par un anesthésiologiste objectif. Chaque concentration à laquelle l'extubation du ML était tentée a été déterminée par des ajustements successifs (suivant des paliers de 0,1\%). Le retrait du ML a été considéré comme réussi s'il n'avait pas provoqué de toux, de tendance à serrer les dents ou de mouvement volontaire global pendant une minute après le retrait.

Résultats : La CAMex d'enflurane nécessaire au retrait du ML sans anesthésie caudale a été de 1,04\% (Intervalle de confiance de 95 $\%, 1,00-1,10$ ) et la CAMex avec anesthésie caudale a été de 0,74 $\%$ (IC de $95 \%, 0,63-0,81$ ). L'analgésie caudale a réduit les besoins d'enflurane de façon significative, $29 \%$ (IC de $95 \%$ I, 22-36\%).

Conclusion : L'analgésie caudale a réduit significativement la CAM d'enflurane lors de l'extubation du ML, d'environ $29 \%$. Cette situation peut s'expliquer par l'effet analgésique du blocage caudal ou les propriétés sédatives de l'anesthésie neuraxiale.

$\mathrm{T}$

HE laryngeal mask airway (LMA) is widely used for ensuring airway patency in the pediatric population with or without regional anesthesia. Caudal analgesia, a relatively simple technique with reliable perioperative analgesia, is the most popular regional anesthesia used in pediatric surgery, especially for operations below the umbilicus. In children, complications associated with removal of the LMA occur more when children

From the Department of Anesthesiology, Plastic Surgery Hospital, Chinese Academy of Medical Sciences, Peking Union Medical College, Beijing, China.

Address correspondence to: Dr. Wen-Jing Xiao, Department of Anesthesiology, Plastic Surgery Hospital, Chinese Academy of Medical

Sciences, Peking Union Medical College, Beijing, China, 100041. E-mail: wenjingxiao@sina.com

Accepted for publication August 20, 2001.

Revision accepted November 15, 2001.

CAN J ANESTH 2002/49:2/pp 194-197 
are awake than when they are deeply anesthetized. ${ }^{1,2}$ Neuraxial anesthesia has been shown to markedly increase the sedative effects of midazolam in humans, ${ }^{3-5}$ which suggests that neural block may itself have sedative properties. We hypothesized that caudal anesthesia would reduce general anesthetic requirements for other, nonsurgical purposes, such as removal of the LMA. Minimum alveolar concentration for LMA extubation (MACex) is defined as adequate general anesthesia to provide satisfactory LMA extubation in $50 \%$ of patients.

We tested whether ropivacaine caudal anesthesia reduces general anesthetic requirements as measured by the MACex of enflurane.

Methods

After obtaining Institutional Human Investigation Committee approval and written, informed consent of the parents, 50 boys, aged three to ten years, ASA physical status I, undergoing elective hypospadias repair were included in this prospective, randomized study. Children were randomized, using a systematic randomsample technique, to one of two treatment groups to receive LMA with or without caudal anesthesia after induction of general anesthesia. Children with an abnormal airway, gastroesophageal reflux, a history of respiratory tract infection in the preceding four weeks, or skin infection of the caudal area were excluded.

Patients were fasted and no premedication was given. After applying standard monitors, general anesthesia was induced via face mask by using sevoflurane in oxygen and $60 \%$ nitrous oxide. Scopolamine 0.01 $\mathrm{mg} \cdot \mathrm{kg}^{-\mathrm{l}}$ was administrated $i v$ after $i v$ access was obtained for infusion of Lactated Ringer's solution. When the depth of anesthesia was considered satisfactory, the LMA was inserted with the opening of the LMA facing posteriorly, followed by rotation through 180. The LMA size was determined by the manufacturer's (previous) guidelines using a size 2 for children $6.5-20 \mathrm{~kg}$ and a size 2.5 for children $20-30 \mathrm{~kg}$. The LMA was deflated and $\mathrm{K}-\mathrm{Y}^{\mathrm{TM}}$ brand sterile lubricating jelly (plain lubricant; Johnson \& Johnson, New Brunswick, NJ, USA) was applied to the back of the mask prior to placement. Sevoflurane was discontinued after induction, and anesthesia was maintained in all patients with enflurane in approximately 60\% nitrous oxide in oxygen with a total inflow of 5 $\mathrm{L} \cdot \mathrm{min}^{-1}$. We used a modified Jackson Rees system for children weighing $<20 \mathrm{~kg}$ and a pediatric circle system for those weighing $20 \mathrm{~kg}$. After successful LMA insertion the child was turned in the left lateral position and a caudal injection of ropivacaine $0.2 \%, 1 \mathrm{~mL} \cdot \mathrm{kg}^{-1}$ was administered in the LMA with caudal anesthesia group, using a short B bevel, 22- gauge needle by the attending anesthesiologist. No caudal anesthesia was administered in the LMA without caudal anesthesia group. Noninvasive mean arterial pressure, heart rate, and oxygen saturation was recorded five minutes before induction of anesthesia, followed by measurement at five-minute intervals during anesthesia. Endtidal carbon dioxide $\left(\mathrm{ETCO}_{2}\right)$ and concentration of enflurane were measured continuously at the elbow of the breathing circuit using a gas monitor $\left(\mathrm{AS} / 3^{\mathrm{TM}}\right.$; Detex, Helsinki, Finland). The concentration of enflurane was adjusted in response to clinical signs. No other analgesic or local anesthetic was used during the operation. All children breathed spontaneously with manual assistance to maintain an $\mathrm{ETCO}_{2}$ ranging from 35 to $50 \mathrm{mmHg}$ during the procedure. Nitrous oxide was discontinued before the end of surgery. At the end of surgery, a predetermined end-tidal enflurane concentration was achieved and a steady state maintained for at least ten minutes to allow equilibration between the alveolar and brain concentrations. Immediately at the end of surgery, oropharyngeal secretions were suctioned gently. The target enflurane concentration received by a particular patient in each group was determined by the response of the previous patient to a higher or lower concentration (with $0.1 \%$ as the step size) using Dixon's up-and-down sequential method. ${ }^{6}$ The first patient in each group was tested at $1.0 \%$ endtidal enflurane, based on results of our previous study. ${ }^{7}$ At the time of LMA extubation, no residual nitrous oxide $>3 \%$ was detected in the end-tidal sample. The LMA was removed and a face mask with jaw lift was applied with $100 \%$ oxygen for five minutes for all children. Patients who developed coughing, teeth clenching, or gross purposeful muscle movements during or within one minute after removal, or patients who developed breath holding, laryngospasm or desaturation to $\mathrm{SpO}_{2}<90 \%$ during or immediately after LMA removal were regarded as not having had successful removal. A result defined as unsuccessful extubation directed an increase by $0.1 \%$ of enflurane for the next patient, whereas if a given patient had a successful extubation, the enflurane concentration was decreased by $0.1 \%$ in the subsequent patient. The anesthesiologist performing the LMA extubation procedure and subsequent assessment was blinded to the concentration used and group allocation. Postoperative pain was assessed and $i v$ morphine or oral tramadol was offered at the discretion of the anesthesiologist.

Demographic data were collected and are presented as mean (SD), median (interquartile range) as appropriate. SD were analyzed using one-way analysis of variance, medians (interquartile ranges) were ana- 
lyzed with Mann-Whitney U test. The up-and-down sequences were analyzed by probit test, which enabled us to derive MACex with $95 \%$ confidence intervals (CI) of the mean. We also analyzed our data by a logistic regression test to obtain the probability of no movement $v s$ end-tidal enflurane concentration. Analyses were performed using Microsoft Excel 97 (Microsoft Inc., Redmond, WA, USA) and SPSS for Windows 10.0 (SPSS Inc., Chicago, IL, USA).

Results

Twenty-five boys were enrolled in each treatment group. Mean age was $5.0 \pm 2.2 \mathrm{yr}$ and $5.4 \pm 2.0 \mathrm{yr}$ in the LMA with or without caudal analgesia groups, respectively. Mean weight was $19.6 \pm 5.8 \mathrm{~kg}$ and 19.7 $\pm 6.5 \mathrm{~kg}$ in the LMA with or without caudal analgesia groups, respectively. Duration of the operation averaged $157.5 \pm 44.9 \mathrm{~min}$ and $152.8 \pm 25.5 \mathrm{~min}$ in the LMA with or without caudal analgesia groups, respectively. Demographic variables did not differ significantly between the two treatment groups. No patient required supplemental $i v$ analgesia. The sequences of successful and unsuccessful LMA extubation are shown in Figure 1. MACex of enflurane in LMA without caudal anesthesia was $1.04 \%$ (95\% CI, $1.00-1.10)$ using the probit test. MACex of enflurane in LMA with caudal anesthesia was $0.74 \% \quad(95 \% \mathrm{CI}$, $0.63-0.81)$. Caudal analgesia significantly reduced enflurane requirements by $29 \%$ (95\% CI, $22-36 \%$ ). The $95 \%$ effective enflurane concentration for smooth extubation was $0.90 \%(95 \% \mathrm{CI}, 0.82-1.34 \%)$ in the LMA with caudal analgesia group, and 1.15 (95\% CI, 1.10-1.42) in the LMA without caudal analgesia group. Logistic regression curves of the probability of no movement for both groups are shown in Figure 2.

\section{Discussion}

The manufacturer $^{8}$ and several authors ${ }^{9-11}$ recommend removal of the LMA after the patient's consciousness and protective upper airway reflexes have returned. Other reports ${ }^{1,2,12}$ suggest that it might be safer to remove the LMA while patients are deeply anesthetized, especially for pediatric patients. The LMA is well tolerated at light levels of anesthesia in adults but not always in children, especially when inhaled anesthetics are used to maintain anesthesia. Laffon et al. ${ }^{1}$ reported a two-fold increase of complications after removal of the LMA in awake compared with deeply anesthetized pediatric patients. LMA removal in the deeply anesthetized patient is used in a variety of settings and after certain surgical procedures, e.g., after intraocular surgery, to prevent a sudden increase in intraocular pressure. Gataure et al. ${ }^{2}$

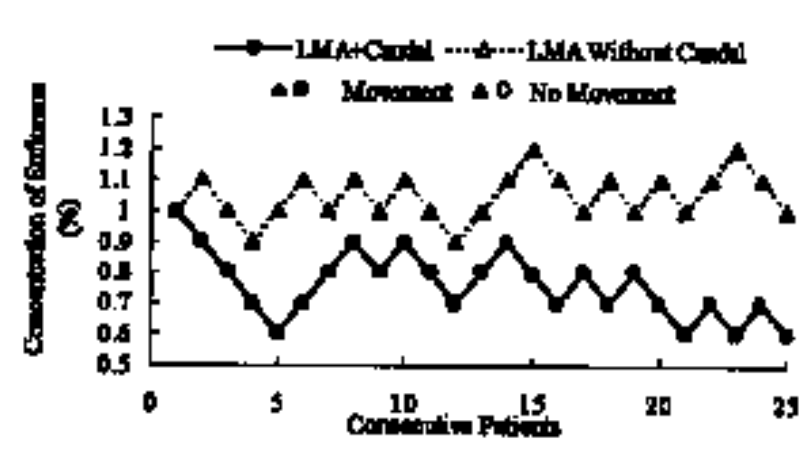

FIGURE 1 Responses of consecutive patients in whom laryngeal mask airway (LMA) extubation was attempted at predetermined end-tidal concentrations of enflurane in oxygen. Circles=LMA with caudal group; triangles=LMA without caudal group.

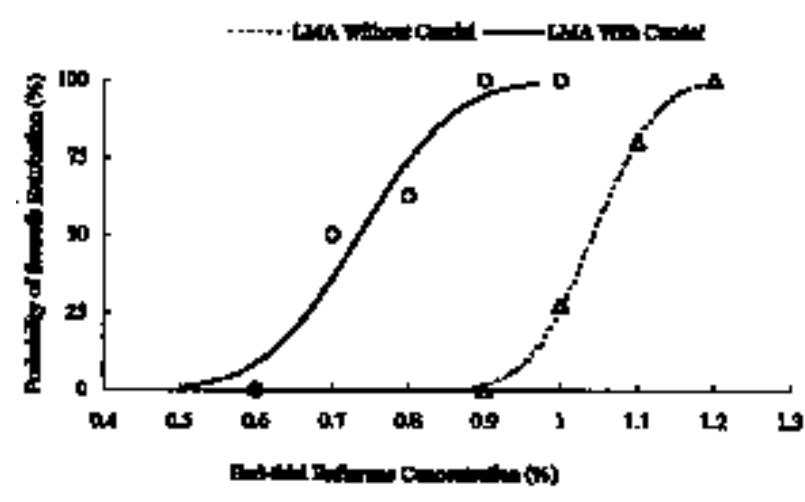

FIGURE 2 Dose-response curve for enflurane plotted from probit analyses of individual end-tidal concentrations and the respective reactions to laryngeal mask airway (LMA) removal in each patient group. Circles=LMA with caudal group; triangles=LMA without caudal group.

found that LMA removal under deep anesthesia could decrease the incidence of coughing, laryngospasm, desaturation, excess salivation, biting, retching, vomiting, and airway obstruction during emergence. The question of how deep anesthesia should be remains. If the LMA is removed at too deep a level of anesthesia, the patient's airway will be left unprotected for a relatively long time. It may be more appropriate to preserve the advantage of deep extubation while reducing the interval between LMA removal and the return of consciousness and protective airway reflexes. Our results help define the concentration of enflurane at which LMA removal can be accomplished safely while minimizing this interval. 
The results of our study show that the MACex of enflurane is $1.04 \%$ in children, and $0.74 \%$ in the presence of caudal analgesia during the operation. A markedly lesser amount of enflurane is needed to provide smooth LMA removal when a combined caudalgeneral technique is used. Thus, caudal blockade decreases general anesthetic requirements at the surgical site, and also at nonsurgical sites. This MACex sparing effect is most likely the result of several mechanisms. First, we speculate that the significant decrease in MACex seen with caudal analgesia is induced by blockade of nociceptive stimuli (afferent pathway) due to caudal anesthesia. Use of combined caudal-general anesthesia may provide a smooth transition to early postoperative analgesia. During the early postoperative period, pain is considered to play the most important role in arousal from anesthesia. ${ }^{13}$ Second, neuraxial anesthesia has been shown to markedly potentiate the sedative effects of midazolam and thiopental in humans,${ }^{3-5}$ and significantly decrease the MAC of sevoflurane, ${ }^{13,14}$ suggesting that neural blockade may itself have sedative properties. Caudal blockade decreases input from sensory and motor afferents. The afferentation theory proposes that tonic sensory and muscle-spindle activity maintains a state of wakefulness. ${ }^{15}$ Eappen et al. ${ }^{16}$ proposed that a decreased afferent input to the brain could lessen excitatory descending modulation of spinal cord motoneurons and suppress motor function.

Placing the sampling catheter between the LMA and the breathing tube potentially contaminates the end-tidal gas with fresh gas. More accurate measurement of end-tidal gas therefore requires sampling from the distal end of the LMA.

In conclusion, caudal analgesia significantly reduced the LMA MACex of enflurane by approximately $29 \%$ in boys undergoing hypospadias repair. Possible mechanisms may be related to the analgesic effect of caudal blockade or to the sedative properties of neuraxial anesthesia.

Acknowledgements

The authors thank Dr. Malachy O. Columb (Consultant in Anaesthesia and Intensive Medicine, South Manchester University Hospital, Withington, United Kingdom), for assistance with statistical analysis; Mr. Jason Carr (Peking Union Medical College, Beijing), for careful critique of the manuscript. The authors also thank Professor Shen-Kai Li and all other members of staff at the Hypospadias Center of Plastic Surgery Hospital for their kind assistance.
References

1 Laffon M, Plaud B, Dubousset AM, Ben Haj'bmida R, Ecoffey $C$ Removal of laryngeal mask airway: airway complications in children, anaesthetized versus awake. Paediatr Anaesth 1994; 4: 35-7.

2 Gataure PS, Latto IP, Rust S. Complications associated with removal of the laryngeal mask airway: a comparison of removal in deeply anaesthetised versus awake patients. Can J Anaesth 1995; 42: 1113-6.

3 Ben-David B, Vaida S, Gaitini L. The influence of high spinal anesthesia on sensitivity to midazolam sedation. Anesth Analg 1995; 81: 525-8.

4 Tverskoy M, Shagal M, Finger J, Kissin I. Subarachnoid bupivacaine blockade decreases midazolam and thiopental hypnotic requirements. J Clin Anesth 1994; 6: 487-90.

5 Tverskoy M, Shifrin V, Finger J, Flyshman G, Kissin I. Effect of epidural bupivacaine block on midazolam hypnotic requirements. Reg Anesth 1996; 21: 209-13.

6 Dixon WJ. Staircase bioassay: the up-and-down method. Neurosci Biobehav Rev 1991; 15: 47-50.

7 Xiao WJ, Deng X. The minimum alveolar concentration of enflurane for laryngeal mask airway extubation in deeply anesthetized children. Anesth Analg 2001; 92: $72-5$.

8 Brain AIJ. The Intravent Laryngeal Mask Instruction Manual, 2nd ed. Berkshire, UK: Brain Medical, 1992.

9 Mason DG, Bingham RM The laryngeal mask airway in children. Anaesthesia 1990; 45: 760-3.

10 Pennant JH, White PF. The laryngeal mask airway. Its uses in anesthesiology. Anesthesiology 1993; 79: 144-63.

11 Vergese C, Smith TGC, Young E. Prospective survey of the use of the laryngeal mask airway in 2359 patients. Anaesthesia 1993; 48: 58-60.

12 O'Neil B, Templeton JJ, Caramico L, Schreiner MS. The laryngeal mask airway in pediatric patients: factors affecting ease of use during insertion and emergence. Anesth Analg 1994; 78: 659-62.

13 Inagaki $\Upsilon$, Mashimo T, Kuzukawa A, Tsuda $\Upsilon$, Yoshiya I. Epidural lidocaine delays arousal from isoflurane anesthesia. Anesth Analg 1994; 79: 368-72.

14 Hodgson PS, Liu SS. Epidural lidocaine decreases sevoflurane requirement for adequate depth of anesthesia as measured by the bispectral index® monitor. Anesthesiology 2001; 94: 799-803.

15 Lanier WL, Iaizzo PA, Milde JH, Sharbrough FW. The cerebral and systemic effects of movement in response to a noxious stimulus in lightly anesthetized dogs. Possible modulation of cerebral function by muscle afferents. Anesthesiology 1994; 80: 392-401.

16 Eappen S, Kissin I. Effect of subarachnoid bupivacaine block on anesthetic requirements for thiopental in rats. Anesthesiology 1998; 88: 1036-42. 